\title{
EXPERIMENTAL INVESTIGATION ON MECHANICAL AND ACOUSTIC PERFORMANCE OF MISCANTHUS - LIME COMPOSITES
}

\author{
F. Ntimugura ${ }^{1 *}$, R. Vinai ${ }^{1}$, A. Harper ${ }^{1}$, P. Walker ${ }^{2}$ \\ ${ }^{1}$ College of Engineering, Mathematics and Physical Sciences, University of Exeter, Exeter, \\ EX4 4QF, UK \\ ${ }^{2}$ BRE Centre for Innovative Construction Materials, Department of Architecture and Civil \\ Engineering, University \\ of Bath, Bath, BA2 7AY, UK \\ *Corresponding author; e-mail: fn246@exeter.ac.uk
}

\begin{abstract}
The environmental burdens attributable to buildings remain relatively high. The built environment is responsible for more than one-third of the global energy consumption and nearly $40 \%$ of global $\mathrm{CO}_{2}$ emissions. In the context of increasing the sustainability of the built environment, biobased building materials have gained a growing interest for their application in building envelopes. Miscanthus giganteus (elephant grass) is a perennial, cost effective and sustainable source of fibres for the development of bio-composites. This experimental study evaluates mechanical and acoustic properties of miscanthus - lime composites for their potential use in renovations and new-build houses, in South West England. The impact of binder to aggregate mass ratio and density on compressive strength is investigated. Moreover, the effect of aggregate particle size on the acoustic performance of miscanthus - lime composites is presented. It is shown that the initial fresh density has little effect on compressive strength compared with that of binder content. The acoustic tests results show that the use of small size particles improves the acoustic performance of miscanthus - lime composites with recorded high transmission loss and sound absorption coefficient values.
\end{abstract}

\section{Keywords:}

Acoustic performance; Bio-based building materials; Compressive strength; Miscanthus concrete.

\section{INTRODUCTION}

Bio-based building materials are made of plant particles or fibres and are practical sustainable alternatives to energy intensive insulation materials used in building envelopes (rock wool, glass wool, extruded polystyrene). The ever-growing awareness of sustainability concerns in the building sector has revitalised the drive for ecodesign; and the use of low carbon building materials has recently regained the interest of researchers, industrial and regulatory bodies. One of the major environmental concerns relates to the reduction of $\mathrm{CO}_{2}$ emissions from buildings. Although the operational energy of buildings has reduced over the past few years, the embodied energy associated with corresponding high levels of insulation has risen (Sunderland, 2015). In addition to low embodied carbon associated with bio-based materials buildings, they exhibit a potential for carbon sequestration (Peñaloza et al., 2016). Plant-based fibres and particles have been extensively investigated and the substantial literature on their incorporation in mineral binder matrices for the production of sustainable insulating building components has been reviewed (Amziane, 2016; Amziane and Collet, 2017). Fibres and particles can be obtained from wood, hemp, straw, sunflower, flax, kenaf (Savastano et al., 2016). Miscanthus (elephant grass) is a perennial grass with high annual established yields that is currently used for bio-energy in the UK and has not yet been considered for building materials at any significant level. Considering its porous microstructure and light weight, it seems appropriate to investigate its use as an aggregate for the development of insulation composite materials (Ntimugura et al., 2020).

A combination of flexible plant aggregates or fibres with a rigid matrix of mineral binders produces composites of elasto-plastic behaviour with large strain values, low strength, and low thermal conductivity. The ability to adjust mix designs to specific performance (high strength or low thermal conductivity) allows potential multiple applications in buildings ranging from floors to roofs. The existing wide variety of binders and aggregates provides high levels of design flexibility in terms of strength and insulation of bio-composites. Since 1990s, hemp-lime composite has remained the most studied bio-based material, and hence, constitutes a valuable reference for the 
development of other bio-aggregate materials. It is a well-established fact that binder content (binder to aggregate mass ratio) is one of the main parameters that influence the mechanical behaviour of bio-composites. Studies by Cérézo (2005) and Collet-Foucault (2004) have shown that the density of composites affects both strength and insulation properties of hemp concretes; constituting an additional essential parameter. In fact, the density of hemp concretes depends on mix design and manufacturing techniques (manual tamping, compaction or projection). This wide variety of parameters allows to produce composites with density values in the range of 270 - $750 \mathrm{~kg} / \mathrm{m}^{3}$. Hemp-lime concretes exhibit low compressive strength values, generally in the range of $0.1-0.2$ $\mathrm{N} / \mathrm{mm}^{2}$. The imperfections due to the arrangement of particles, the flexibility of bio-aggregates and the resulting macro-porous composites are responsible for low compressive strength and Young's modulus values. Nonetheless, Nguyen et al. (2009) have shown that compaction, when applied to composites of low binder content can significantly increase their compressive strength. In fact, high compaction increases the compactness of samples leading to increased strength. While compaction has a rather moderate effect on stiffness, it significantly increases ductility. Tronet et al. (2016) reported strength value of $4.74 \mathrm{~N} / \mathrm{mm}^{2}$ achieved by compaction.

Glé (2013) conducted an in-depth investigation of the acoustic properties of hemp-lime composites. In fact, hemp and other plant-based materials exhibit a porous structure that enables the conversion of sound energy to heat inside the pore walls. The acoustic performance of hemp-lime composites was investigated under the $1 / 3$ octave frequencies $(0.5,1$ and $2.0 \mathrm{kHz})$ for density values in the range of $469-583 \mathrm{~kg} / \mathrm{m}^{3}$ by Kinnane et al. (2016). The authors reported values of sound absorption coefficients in the range of $0.32-0.49$ at $500 \mathrm{~Hz}$ and $0.26-0.53$ at $2.0 \mathrm{kHz}$. The increase of binder content reduces sound absorption (Cérézo, 2005). Glé et al. (2011) studied the influence of particle size distribution, density, and binder to aggregate ratio; and reported values of sound absorption coefficients in the range of $0.2-0.5$. Hemp-lime is a composite material of high porosity $(\sim 80 \%)$ (Arnaud and Gourlay, 2012) and a complex porous structure at three scales: macropores (particles arrangement), mesopores (binder/particles interface) and micropores (binder matrix). This complex porous nature makes the acoustic investigations of bio-based composites particularly challenging. Considering the type of mineral binders, cement-based composites exhibit low sound absorption compared to lime-based composites (Glé et al., 2011).

Chen et al. (2017) investigated mechanical and acoustic performance of miscanthus-cement composites. The authors reported compressive strength values around $5.21 \mathrm{~N} / \mathrm{mm}^{2}$. The reduction of particle size of aggregates (2-4 $\mathrm{mm}$ to $0-2 \mathrm{~mm})$ reduced compressive strength by half $(50 \%)$. Nevertheless, the specific strength $\left(\mathrm{N} / \mathrm{mm}^{2} \mathrm{per}\right.$ $\mathrm{kg} / \mathrm{m}^{3}$ ) of miscanthus-cement composites remains slightly lower than that of common lightweight composites and slightly higher than that of other bio-based lightweight composites. The increase of miscanthus content increased both the sound absorption ( $\alpha$ in the range 0.28-0.63) and the frequency of the absorption peak $(700-1250 \mathrm{~Hz}$ ) (Chen et al., 2017). Bio-based building materials for insulation have numerous benefits compared to standard materials, and the use of miscanthus-lime for the production of insulating materials can have significant effects on (Wyk, 2007):

1. The environmental profile: raw materials from miscanthus are renewable and harvested annually. The application of miscanthus concrete in wall assemblies can store $~ 135 \mathrm{~kg} \mathrm{CO} 2 \mathrm{eq} . / \mathrm{m}^{3}$ (Ntimugura et al., 2021)

2. The Human health: there are no volatile organic compound emissions associated with bio-composites compared to synthetic materials (plywood, fibreboards). Hence, miscanthus composites could provide high levels of indoor air quality to the occupants. Moreover, there are no concerns about the handling of bio-composites; hence high level of health and safety at both the manufacturing and installation stages are achievable.

3. The Production cost: the local availability of raw materials (bio-aggregates) and low processing energy, can allow the production of low-cost composites from miscanthus.

The incorporation of miscanthus in cement or lime has been studied recently and its use in composite materials seems to be a plausible potential for sustainable insulation materials (Moll et al., 2020). A chemical, morphological and technical investigation of the suitability of miscanthus in lightweight concrete was conducted (Pude et al., 2005); and the production of panels based on miscanthus-organic binder composites attempted (Eschenhagen et al., 2019). However, miscanthus-lime composites have not yet been significantly investigated. This study investigates the impact of binder to aggregate ratio on mechanical performance and the effects of aggregate size on sound transmission loss and acoustic absorption of miscanthus-lime concretes.

\section{CHARACTERIZATION OF MATERIALS AND EXPERIMENTAL METHODS}

Miscanthus was sourced from Miscanthus Nursery Ltd (Somerset, UK). The material was provided un-sieved and was subsequently subdivided in three ranges of particle size: 5-2.36 mm (size 1), 2.36-1.18 mm (size 2) and < $1.18 \mathrm{~mm}$ (size 3). The characterisation tests of miscanthus shives for particle size distribution, water absorption and density were performed using the recommendations in RILEM TC 236-BBM (Amziane et al., 2017). The length of particles of miscanthus shives was in the range of $2-10 \mathrm{~mm}$. The particle size distribution curve shown in Fig.1 (a) was obtained using mechanical sieving method. The median width of particles was in the range of $3.72-4.07 \mathrm{~mm}$. Miscanthus aggregates had an initial moisture content of $9.8 \%$ and a bulk density of $132.5 \mathrm{~kg} / \mathrm{m}^{3}$. The water absorption kinetics curves shown in Fig. 1 (b) exhibit two distinct steps: a slow phase of water absorption (at 12 hours) preceded by a high rate of water absorption (0-800 minutes). The water absorption kinetics presented in this study is consistent with absorption reported by Chen et al. (2017). Compressive strength tests were conducted on miscanthus concrete cubic samples of $100 \mathrm{~mm}$ using MCC8 multi-test frame, under load control with a pre-load of $\sim 100 \mathrm{~N}$ and a loading speed of $50 \mathrm{~N} / \mathrm{s}$. Three mix designs were tested for compressive strength to evaluate the effect of binder to aggregate mass ratio (b/a) and water to binder mass ratio (w/b). Mix designs were referred to as follows: Ib-mw (1.1 b/a and $0.86 \mathrm{w} / \mathrm{b})$; mb-lw (2.15 b/a and 0.55 w/b); hb-lw (3.48 b/a 
and $0.55 \mathrm{w} / \mathrm{b}$ ). Samples were manufactured and cured in indoor standard conditions (ISC): $25^{\circ} \mathrm{C}$ and $50 \%$ relative humidity $(\mathrm{RH})$, for 28 and 60 days before compressive strength tests.

Lime-based bio-composites exhibit improved acoustic performance compared to cement-based composites (Glé et al., 2011). Moreover, lime has a high carbonation potential that improves its environmental profile. Natural hydraulic lime (NHL 3.5) and ground granulated blast furnace slag (GGBS) were henceforth selected as basic binder and pozzolanic constituents, respectively. Fig. 2(a) shows the XRD patterns of GGBS with its characteristic amorphous hump at $\sim 30^{\circ} 2 \theta$, and the microstructure observed under scanning electron microscope (SEM). The XRD patterns of NHL 3.5 and its microstructure are presented in Fig. 2(b). The mineralogical composition of lime confirmed the presence of Portlandite, Calcite and Alite as the main minerals.
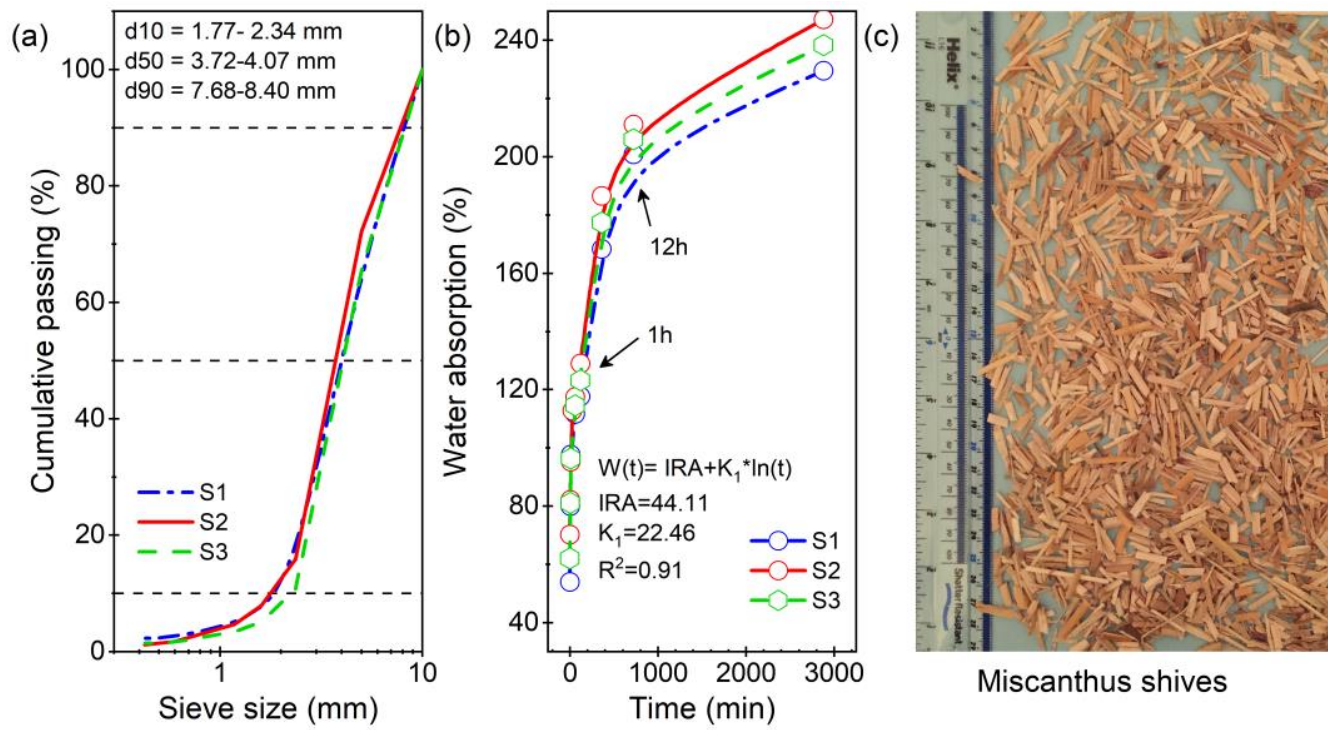

Fig. 1: (a) Particle size distribution of miscanthus by mechanical sieving (250 g), (b) water absorption of the aggregates (S1, S2 and S3 refer to samples of the same material at three different testing times) and (c) miscanthus aggregates $(2.36-1.18 \mathrm{~mm})$.

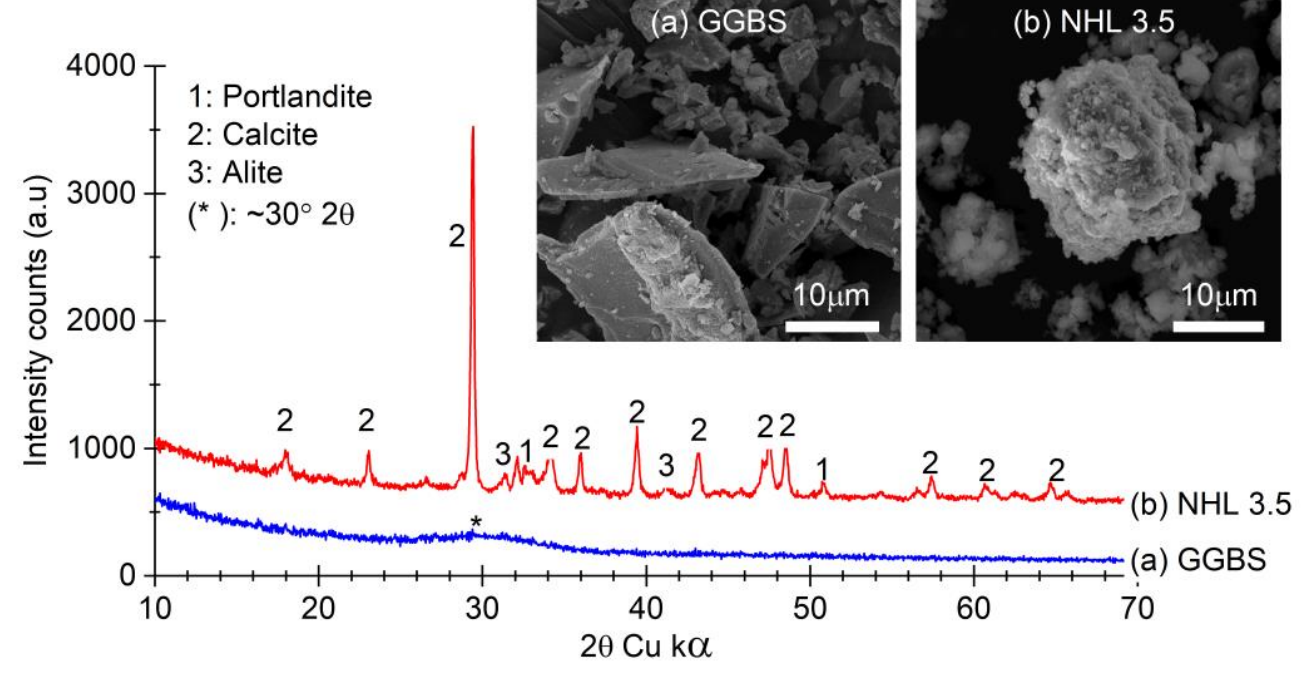

Fig. 2: The XRD patterns and SEM micrographs at $5 \mathrm{kX}$ magnification of raw lime NHL 3.5 and GGBS.

The acoustic tests were conducted using an airborne impedance tube of $100 \mathrm{~mm}$ diameter to measure the normal incidence transmission loss and sound absorption coefficients over the frequency range of $50-1600 \mathrm{~Hz}$ in accordance with ASTM E2611-17 (E33 Committee, 2017). Samples of $100 \mathrm{~mm}$ diameter and $50 \mathrm{~mm}$ thickness, previously dried at $90^{\circ} \mathrm{C}$, were fitted in the impedance tube with a sealant. The loudspeaker (emitter) generates random plane waves of sound that hit the sample. Parts of the incident waves are reflected, transmitted, and absorbed. The acoustic tests were conducted on samples that contain $80 \%$ of $5-2.35 \mathrm{~mm}$ and $20 \%$ of $2.36-1.18$ $\mathrm{mm}$ aggregates. The obtained results were compared to those of samples that contain $80 \%$ of $2.36-1.18 \mathrm{~mm}$ and $20 \%$ of $1.18-0 \mathrm{~mm}$ aggregates. These compositions were made to optimise the macro-porosity of samples while using all ranges of available particle sizes. The b/a ratio was fixed at 2.15 using a blend of $70 \%$ NHL3.5 $+30 \%$ GGBS and the w/b ratio was 0.55 for all samples tested for acoustic absorption ( $\alpha$ ) and transmission loss (TL). Two samples of $100 \mathrm{~mm}$ diameter and $150 \mathrm{~mm}$ thickness were manufactured and cut into three slices of $50 \mathrm{~mm}$. The upper and lower pieces (respectively Up. and Lw. samples) were tested for transmission loss and acoustic absorption coefficient. 


\section{RESULTS AND DISCUSSIONS}

\subsection{Impact of Binder Content on Mechanical Properties}

The stress-strain curves for low and medium binder content composites ( $b / a=1.1$ and 2.15 , resp.) are shown in Fig.3 (a) and (b), respectively. Both composites show a similar behaviour with strain-hardening at increasing stress values, lack of failure peaks and comparable initial Young's modulus values ( $E_{\text {in }}$ ). Compression curves exhibit a two-steps kinetics typical of hemp concretes (Cérézo, 2005), i.e., an initial elastic phase followed by an increasing inflexion of the curve attributable to the growth of cracks in the binder-matrix interface. This phase leads to strain hardening of tested samples due to the shift to fibre-cohesion load path. Comparable descriptions of mechanical behaviour of bio-based materials were reported in literature (Kioy, 2013; Mazhoud, 2017).

Fig. 3 (b) shows the stress-strain curves of samples loaded in directions parallel and perpendicular to the casting direction. It shows that miscanthus concrete has a remarkable anisotropic behaviour in compression. The loading in perpendicular direction exhibits high initial stiffness and brittle behaviour compared to the ductile, strainhardening behaviour observed in parallel loading. Similar behaviour was observed for hemp-lime (Williams et al., 2018) and sunflower stems concretes (Nozahic et al., 2012).
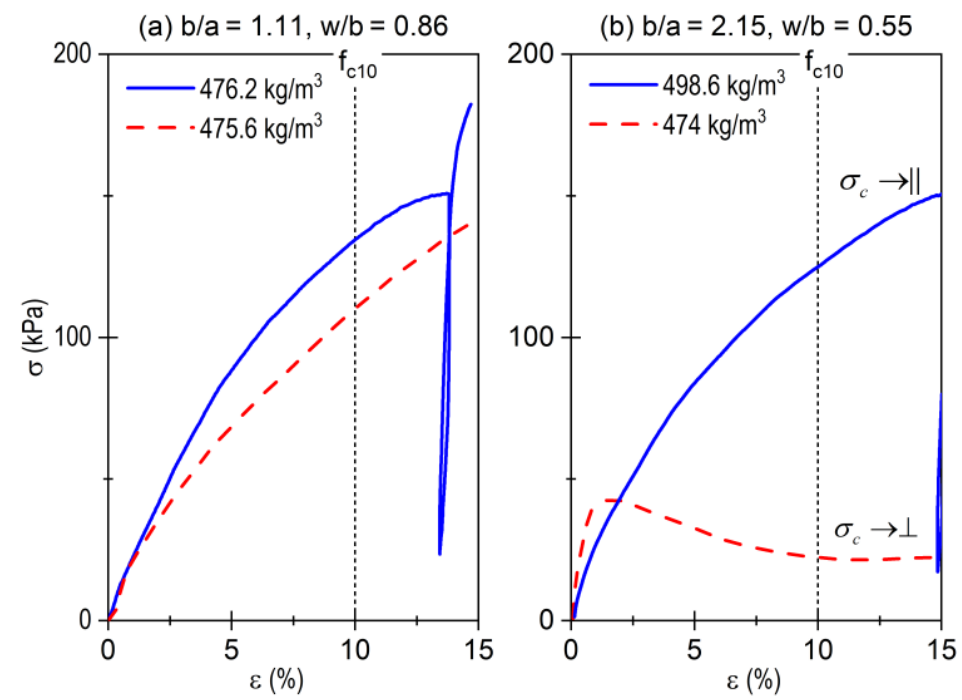

Fig. 3: Compressive behaviour of low and medium binder content miscanthus composites after 28 days of indoor standard curing conditions: ISC. (a) stress-strain curves of composites of low binder content (b/a = 1.11); (b) composites of medium binder content $(b / a=2.15)$. An anisotropic behaviour is displayed with different parallel and perpendicular loading curves.
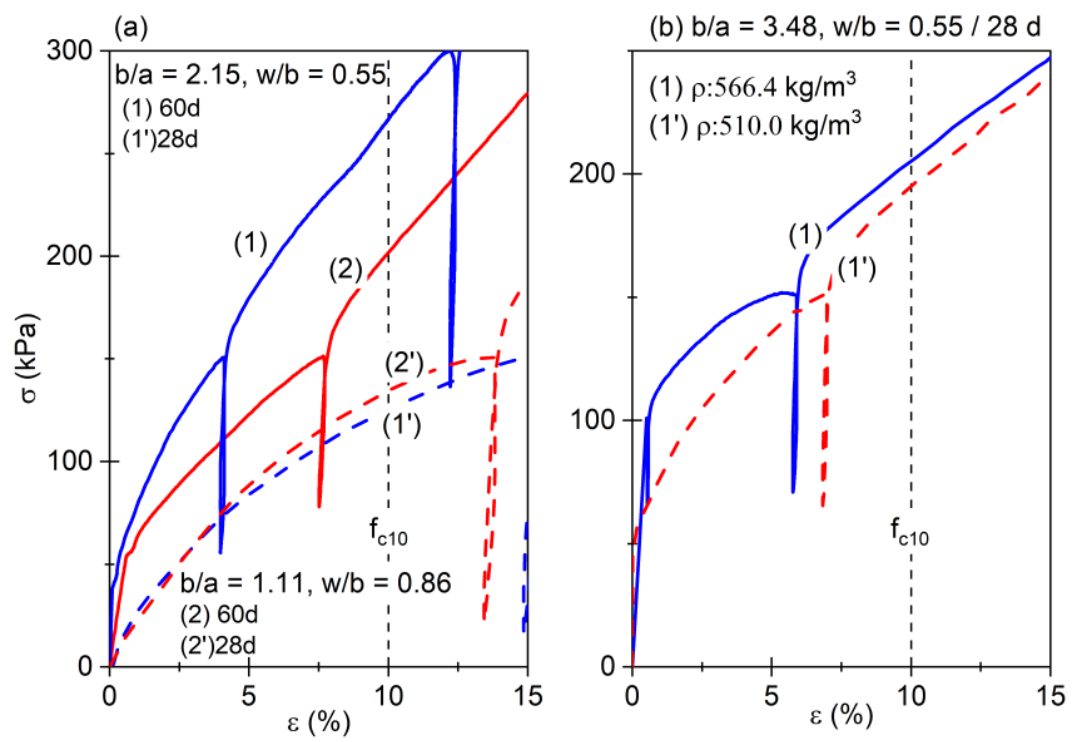

Fig. 4: (a) The impact of curing time on compressive behaviour of low and medium binder content ( $b / a=1.11$ and 2.15) composites (28d - 60d: 28 - 60 days of ISC conditions), (b): compressive behaviour of high binder content miscanthus composites ( $b / a=3.48)$, after 28 days ISC.

Fig. 4(a) shows compression curves of miscanthus composites of low and medium binder content $(\mathrm{b} / \mathrm{a}=1.11$ and $\mathrm{b} / \mathrm{a}=2.15)$ after 28 and 60 days of ISC. Fig. 4(b) presents compression curves of composites of high binder content $(b / a=3.48)$ after 28 days of ISC. After 28 days, composites of low and medium binder content exhibit a similar behaviour. However, after 60 days, samples of medium binder content show higher stiffness than those of low binder content. This can be attributed to an increased filler-effect of binder reducing voids between 
aggregates and hence, increasing the compactness of composites. An additional effect on the improvement of strength and stiffness after 60 days of curing results from higher carbonation of lime matrix. The carbonation of binder will increase volume $(\sim 12 \%)$ without the swelling of the matrix but with a reduction of pores size (Magniont and Escadeillas, 2017). As a result, the strength increases over time. The compressive stress at $10 \%$ strain $\left(f_{c 10}\right)$ and the initial Young's modulus values (Ein.) of samples tested after 28 days of ISC are shown in Fig. 5(a) and (b), respectively. Composites of low and medium binder content show comparable average $\mathrm{f}_{\mathrm{c} 10}$ values $(122.33 \mathrm{kPa}$ and $125 \mathrm{kPa}$ resp.). However, composites of high binder content exhibit relatively high values of $\mathrm{f}_{\mathrm{c} 10} \sim 200 \mathrm{kPa}$.

The initial Young's modulus values show a positive correlation with the binder content of samples as shown in Fig. 5(b). However, the comparison with existing literature values of Young's modulus, remains problematic and it cannot be considered straightforward. In fact, a wide range of $E_{\text {in }}$ values depend on the geometry of samples and loading conditions, in addition to composites inherent characteristics and assumptions in $\mathrm{E}_{\text {in }}$ calculation. Cérézo (2005) assumed the validity of small deformations hypothesis, for a variety of mix designs and within a curing period of 12 months; and reported values of 4-32 MPa for 10 wt.\% binder content $\left(250 \mathrm{~kg} / \mathrm{m}^{3}\right)$ and $32-95 \mathrm{MPa}$ for $19-29$ wt.\% binder content (density in range $350-500 \mathrm{~kg} / \mathrm{m}^{3}$ ) on samples of $160 \mathrm{~mm}$ diameter and $320 \mathrm{~mm}$ height. The values of $E_{\text {in }}$ reported here are in the range of 1.2-1.8 MPa and were obtained on cubic samples of $100 \mathrm{~mm}$.

The correlation between binder content and both $f_{c 10}$ and density; and the correlation between density, $f_{c 10}$ and initial Young modulus of samples are shown in Fig. 6(a),(b), and Fig. 7(a) and (b), respectively. The binder content has a direct effect on compressive strength that is more pronounced on samples of high binder content $(b / a=3.48)$ than on those of low binder content $(b / a=1.11$ and $b / a=2.15)$. The same observation applies to density. A good correlation between density and $\mathrm{f}_{\mathrm{c} 10}$ was observed, as well as between density and $\mathrm{E}_{\text {in. }}$ However, outlying values corresponding to high binder content samples can be noticed.
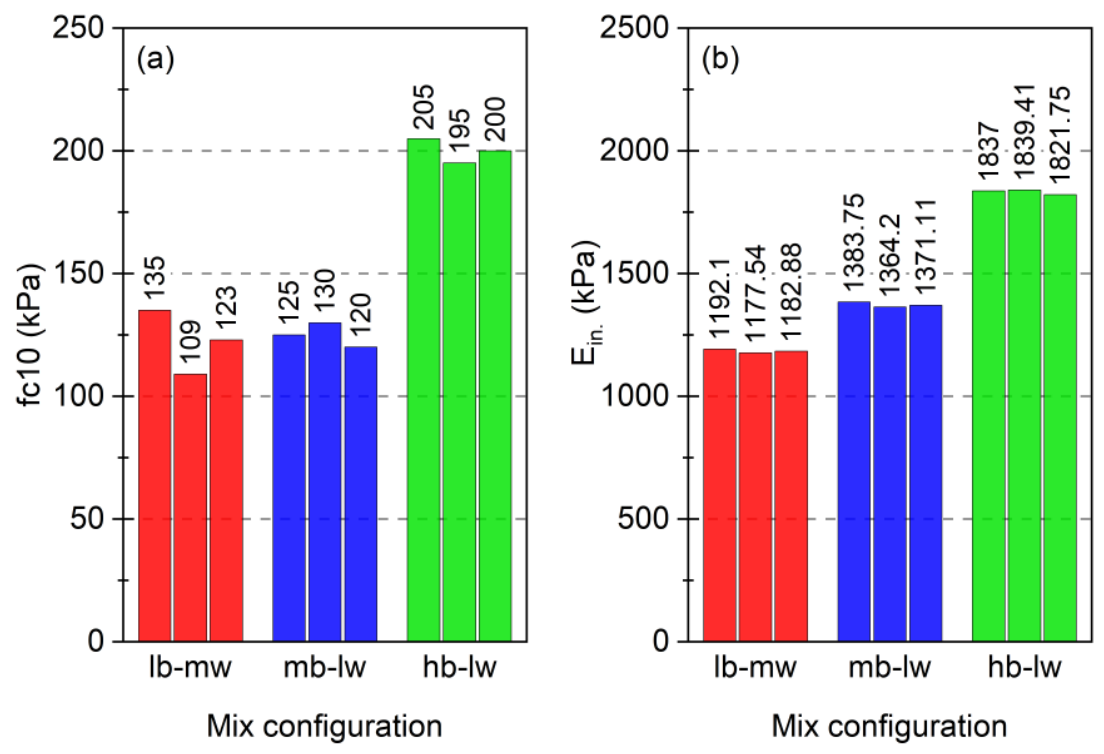

Fig. 5: (a) The evolution of strength at $10 \%$ strain for different mixes; (b) the evolution of the $E_{\text {in }}$ for various mixes of miscanthus concretes. Values are obtained after 28 days of curing at indoor standard conditions (ISC): $25^{\circ} \mathrm{C}$ and $50 \%$ relative humidity $(R H)$.
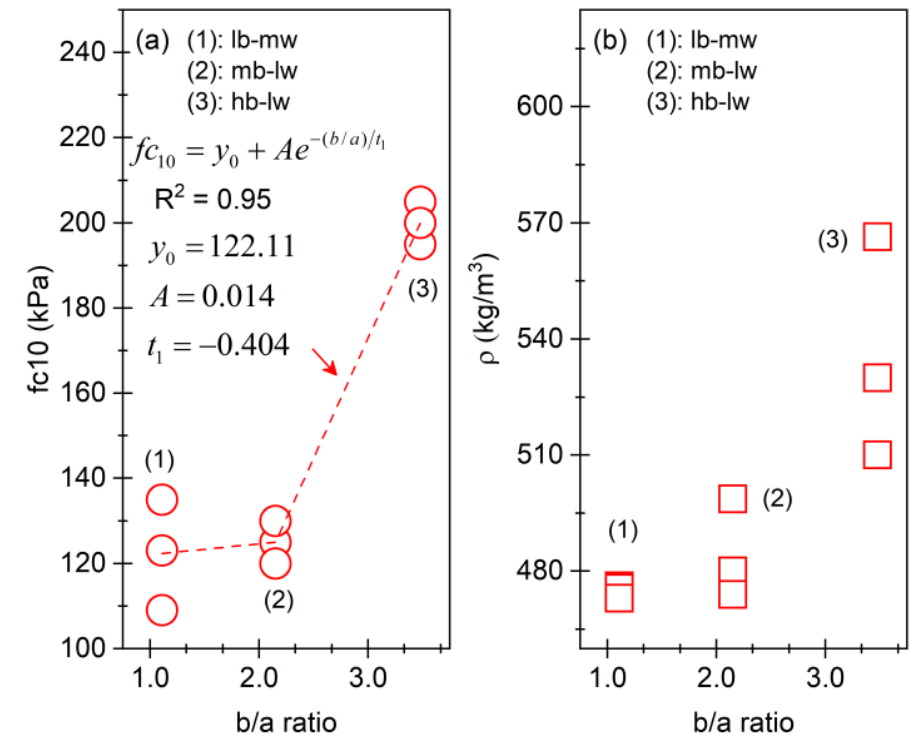

Fig. 6: (a) The effect of binder content on strength ( $\left.f_{c 10}\right)$; (b) the effect of binder content on density of miscanthus concretes (after 28 days of ISC). 

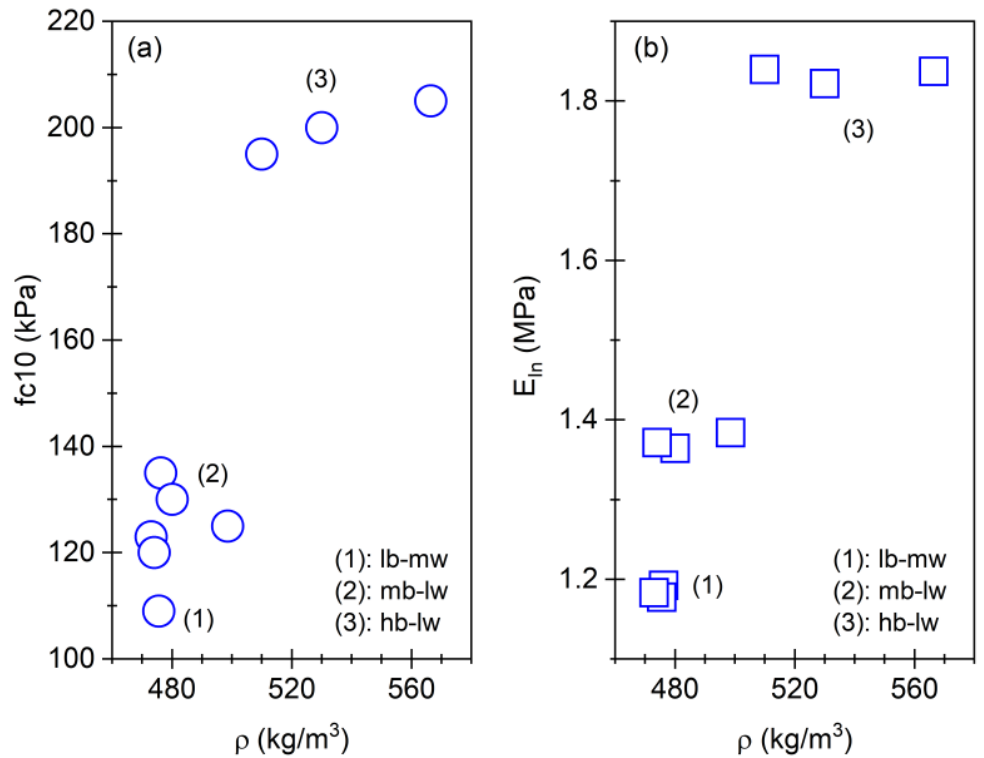

Fig. 7: (a) The correlation between density and strength $\left(f_{c 10}\right)$ and $(b)$ the correlation between density and Young's modulus (Ein), after 28 days of ISC.

\subsection{Effect of Particle Size on Acoustic Performance of miscanthus concrete}

The results from acoustic tests on miscanthus-lime concretes that incorporate $80 \%$ of $5-2.36 \mathrm{~mm}$ particles and $20 \%$ 2.36-1.18 mm particles, and those made of $80 \%$ of $2.36-1.18 \mathrm{~mm}$ particles and $20 \%$ of $1.18-0.00 \mathrm{~mm}$ particles are discussed in this section. Samples were referred to as Up. and Lw., respectively for upper and lower slices of specimens (considering compaction direction). Fig.8 (a) shows that transmission loss values of all tested samples increase from low to high frequency values. Samples made of small-size particles exhibit higher transmission loss values $(10-30 \mathrm{~dB})$ than those made of large-size particles $(3.5-12 \mathrm{~dB})$. There is a possibility that mixing small-size aggregates increases tortuosity of miscanthus concretes, resulting in higher normal incidence transmission loss (TL) values (Shravage et al., 2010). However, curves of sound absorption coefficients show stable signals around $0.4-0.7 \alpha$ in the frequency range of $500-900 \mathrm{~Hz}$ (Fig.8 (b)). The sound absorption of composites, in that range of frequency values, shows no clear trend regarding the effect of particle size. However, predominantly low absorption coefficients $(\sim 0.4)$ were recorded for the upper slice of samples with small-size particles compared to the low slice of the same sample $(\sim 0.6)$ in the frequency range of $1.0-1.6 \mathrm{kHz}$. This relatively high discrepancy can be related to the variability of samples internal structure along their heights. A clear relation between particle size and transmission loss of composites was established, with distinct and substantially distinguishable TL profiles. It was noticed that the use of small-size particles increases the transmission loss of miscanthus concretes. However, no conclusive outcomes were deduced from sound absorption profiles of tested samples. Testing a higher number of samples might be able to assist confirming the observed trends.

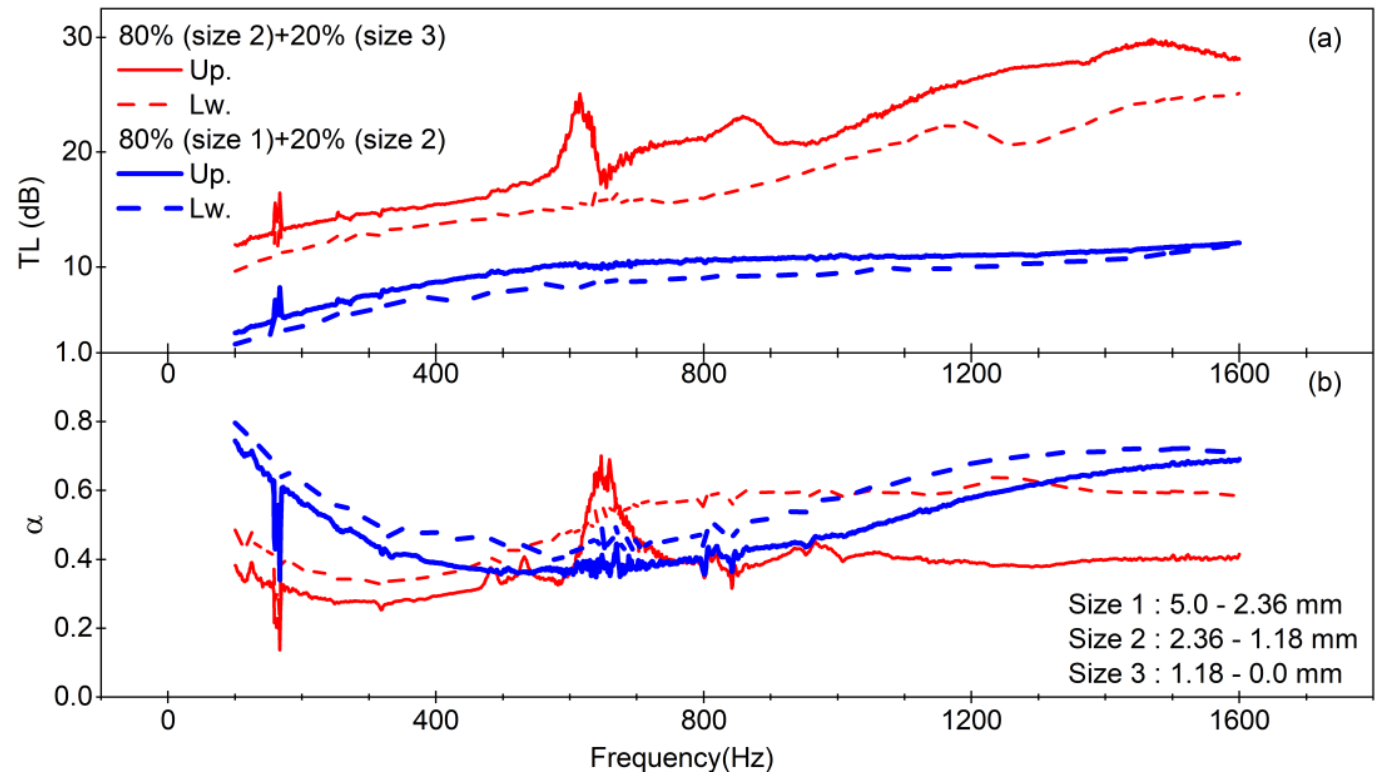

Fig. 8: (a) Profiles of Transmission loss (TL) values and (b) sound absorption coefficient ( $\alpha$ ) of miscanthus - lime concretes made of large-size aggregates and those made of small-size aggregates. 


\section{CONCLUSION AND PERSPECTIVES}

This study investigates the influence of binder content on mechanical behaviour and that of particle size on acoustic properties of miscanthus-lime concretes. The mechanical behaviour of miscanthus concretes depends on binder content which affects both strength and stiffness. Composites of low binder to aggregate ratio (1.1 to $2.15 \mathrm{~b} / \mathrm{a})$ show similar mechanical performance and behaviour after 28 days of curing in ISC (25ㅇ and $50 \% \mathrm{RH})$. However, composites of higher binder to aggregate ratio exhibit high stiffness and compressive strength at 60 days. This was attributed to improved compactness and hardening due to progressing carbonation of the binder matrix. The following conclusions can be drawn from the mechanical standpoint :

- Composites of similar compressive strength values at $10 \%$ strain are produced when using low and medium binder to aggregate mass ratio values (122.33 kPa and $125 \mathrm{kPa}$ for 1.11 and $2.15 \mathrm{~b} / \mathrm{a}$, respectively). However, increasing binder to aggregate ratio to 3.48 increases compressive strength to $200 \mathrm{kPa}$.

- Compressive strength values are less affected by binder to aggregate ratio values after 28 days compared with 60 days of curing. Both composites of low and medium binder content (1.11 and $2.15 \mathrm{~b} / \mathrm{a}$, resp.) exhibit comparable strength values after 28 days. However, strength values increase by $32.5 \%$ when the binder to aggregate ratio increases from 1.11 to 2.15 after 60 days. This is associated with the gradual kinetics of carbonation of binder matrix, with a more pronounced effect after 60 days compared to 28 days.

The influence of particle size distribution on transmission loss and acoustic absorption was also assessed. It was observed that the incorporation of small-size particles in miscanthus-lime concretes leads to transmission loss values in the range of $10-30 \mathrm{~dB}$. The transmission loss values decreased to $3.5-12 \mathrm{~dB}$ when large-size particles were used. The obtained results suggest no significant effect of particle size on sound absorption. Nonetheless, relatively low values of sound absorption were observed for the upper slices of small-size particles samples at high frequency range $(1.0-1.6 \mathrm{kHz})$.

The results showed that miscanthus can be used effectively as a bio-aggregate to develop composites with acceptable strength and acoustic performance. However, further research is needed to extend investigated parameters to various types of binders and manufacturing processes. Correlations between porosity of samples with both mechanical and acoustic properties have to be assessed, and the influence of aggregate size on mechanical properties shall be investigated in forthcoming experiments. An increased number of tested samples is required to draw statistically robust correlations between the acoustic properties and parameters of the composites.

\section{ACKNOWLEDGMENTS}

This project is part of the ongoing research at the University of Exeter, College of Engineering Mathematics and Physical Sciences (CEMPS). It is supported by a NERC GW4+ Doctoral Training Partnership studentship from the Natural Environment Research Council (NERC) and the National Productivity Investment Fund (NPIF) [NE/R011621/1]. The authors are thankful for the support and additional funding from CASE partners, Miscanthus Nursery Limited and Agrikinetics Limited. The contribution of Jones Nicholas (University of Exeter, CEMPS and Qinetic), in conducting acoustic tests is gratefully acknowledged.

\section{REFERENCES}

Amziane, S., 2016. Overview on bio-based building material made with plant aggregate. RILEM Technical Letters 9

Amziane, S., Collet, F. (Eds.), 2017. Bio-aggregates Based Building Materials: State-of-the-Art Report of the RILEM Technical Committee 236-BBM, RILEM State-of-the-Art Reports. Springer Netherlands. https://doi.org/10.1007/978-94-024-1031-0

Amziane, S., Collet, F., Lawrence, M., Magniont, C., Picandet, V., Sonebi, M., 2017. Recommendation of the RILEM TC 236-BBM: characterisation testing of hemp shiv to determine the initial water content, water absorption, dry density, particle size distribution and thermal conductivity. Mater Struct 50, 167. https://doi.org/10.1617/s11527-017-1029-3

Arnaud, L., Gourlay, E., 2012. Experimental study of parameters influencing mechanical properties of hemp concretes. Construction and Building Materials 28, 50-56. https://doi.org/10.1016/j.conbuildmat.2011.07.052

Cérézo, V., 2005. Propriétés mécaniques, thermiques et acoustiques d'un matériau à base de particules végétales : approche expérimentale et modélisation théorique ( $\mathrm{PhD}$ thesis). http://www.theses.fr. Lyon, INSA.

Chen, Y., Yu, Q.L., Brouwers, H.J.H., 2017. Acoustic performance and microstructural analysis of bio-based lightweight concrete containing miscanthus. Construction and Building Materials 157, 839-851. https://doi.org/10.1016/j.conbuildmat.2017.09.161

Collet-Foucault, F., 2004. Caractérisation hydrique et thermique de matériaux de génie civil à faibles impacts environnementaux (PhD thesis). http://www.theses.fr. Rennes, INSA.

E33 Committee, 2017. Test Method for Measurement of Normal Incidence Sound Transmission of Acoustical Materials Based on the Transfer Matrix Method. ASTM International. https://doi.org/10.1520/E2611-17 
Eschenhagen, A., Raj, M., Rodrigo, N., Zamora, A., Labonne, L., Evon, P., Welemane, H., 2019. Investigation of Miscanthus and Sunflower Stalk Fiber-Reinforced Composites for Insulation Applications. Advances in Civil Engineering 2019, 1-7. https://doi.org/10.1155/2019/9328087

Glé, P., 2013. Acoustique des Matériaux du Bâtiment à base de Fibres et Particules Végétales - Outils de Caractérisation, Modélisation et Optimisation (PhD thesis). INSA de Lyon.

Glé, P., Gourdon, E., Arnaud, L., 2011. Acoustical properties of materials made of vegetable particles with several scales of porosity. Applied Acoustics 72, 249-259. https://doi.org/10.1016/j.apacoust.2010.11.003

Kinnane, O., Reilly, A., Grimes, J., Pavia, S., Walker, R., 2016. Acoustic absorption of hemp-lime construction. Construction and Building Materials 122, 674-682. https://doi.org/10.1016/j.conbuildmat.2016.06.106

Kioy, S., 2013. Lime-hemp composites: compressive strength and résistance to fungal attacks. MEng dissertation, recalled in Appendix 1: Resistance to compression and stress-strain properties, in: Hemp Lime Construction, A Guide to Building With Hemp Lime Composites. IHS BRE Press.

Magniont, C., Escadeillas, G., 2017. Chemical Composition of Bio-aggregates and Their Interactions with Mineral Binders, in: Amziane, S., Collet, F. (Eds.), Bio-Aggregates Based Building Materials : State-of-the-Art Report of the RILEM Technical Committee 236-BBM, RILEM State-of-the-Art Reports. Springer Netherlands, Dordrecht, pp. 1-37. https://doi.org/10.1007/978-94-024-1031-0_1

Mazhoud, B., 2017. Elaboration et caractérisation mécanique, hygrique et thermique de composites bio-sourcés (PhD thesis). INSA de Rennes.

Moll, L., Wever, C., Völkering, G., Pude, R., 2020. Increase of Miscanthus Cultivation with New Roles in Materials Production-A Review. Agronomy 10, 308. https://doi.org/10.3390/agronomy10020308

Nguyen, T.-T., Picandet, V., Amziane, S., Baley, C., 2009. Influence of compactness and hemp hurd characteristics on the mechanical properties of lime and hemp concrete. European Journal of Environmental and Civil Engineering 13, 1039-1050. https://doi.org/10.1080/19648189.2009.9693171

Nozahic, V., Amziane, S., Torrent, G., Saïdi, K., De Baynast, H., 2012. Design of green concrete made of plantderived aggregates and a pumice-lime binder. Cement and Concrete Composites 34, 231-241. https://doi.org/10.1016/j.cemconcomp.2011.09.002

Ntimugura, F., Vinai, R., Harper, A., Walker, P., 2020. Mechanical, thermal, hygroscopic and acoustic properties of bio-aggregates - lime and alkali - activated insulating composite materials: A review of current status and prospects for miscanthus as an innovative resource in the South West of England. Sustainable Materials and Technologies e00211. https://doi.org/10.1016/j.susmat.2020.e00211

Ntimugura, F., Vinai, R., Harper, A.B., Walker, P., 2021. Environmental performance of miscanthus-lime lightweight concrete using life cycle assessment: Application in external wall assemblies. Sustainable Materials and Technologies 28, e00253. https://doi.org/10.1016/j.susmat.2021.e00253

Peñaloza, D., Erlandsson, M., Falk, A., 2016. Exploring the climate impact effects of increased use of bio-based materials in buildings. Construction and Building Materials 125, 219-226. https://doi.org/10.1016/j.conbuildmat.2016.08.041

Pude, R., Treseler, C.H., Trettin, R., Noga, G., 2005. Suitability of Miscanthus genotypes for lightweight concrete.

Savastano, H., Santos, S.F., Fiorelli, J., Agopyan, V., 2016. 19 - Sustainable use of vegetable fibres and particles in civil construction, in: Khatib, J.M. (Ed.), Sustainability of Construction Materials (Second Edition), Woodhead Publishing Series in Civil and Structural Engineering. Woodhead Publishing, pp. 477-520. https://doi.org/10.1016/B978-0-08-100370-1.00019-6

Shravage, P., Jain, S., Karanth, N., 2010. Effect of intrinsic parameters on sound absorption and transmission loss: A parametric study. The Journal of the Acoustical Society of America 127, 1735-1735. https://doi.org/10.1121/1.3383465

Sunderland, L., 2015. Tackling embodied carbon in buildings. UK Green Building Council 16.

Tronet, P., Lecompte, T., Picandet, V., Baley, C., 2016. Study of lime hemp concrete (LHC) - Mix design, casting process and mechanical behaviour. Cement and Concrete Composites 67, 60-72. https://doi.org/10.1016/j.cemconcomp.2015.12.004

Williams, J., Lawrence, M., Walker, P., 2018. The influence of constituents on the properties of the bio-aggregate composite hemp-lime. Construction and Building Materials 159, 9-17. https://doi.org/10.1016/j.conbuildmat.2017.10.109

Wyk, L.V., 2007. The Application of Natural Fibre Composites in Construction: A Research Case, in: Study', Sixth International Conference on Composite Science and Technology, Durban, South Africa. pp. 22-24. 